\title{
リン酸ジ（2-エチルヘキシル)/4-メチル-2- ペンタノン抽出による鉄(III)の分離除去
}

\author{
浅野 比* ·板橋 英之* . 川本 博*
}

Separation of Iron(III) by Di(2-ethylhexyl)phosphate/4-Methyl-2-pentanone Extraction

Hitoshi AsAno, Hideyuki ITABASHI and Hiroshi KaWAMOTO

\section{1. 緒言}

鉄鋼中の微量成分を分析することは，鉄鋼の品質を評価 する上で極めて重要である。しかし，鉄鋼中の微量成分を 分析する場合，マトリックスである鉄が妨害成分となるた め，それら成分からの鉄の分離は必須の前処理操作となる。 溶媒抽出法は操作が簡便で, 特別な装置も必要としないこ とから，鉄鋼を溶解した試料から鉄(III)を除去する方法と して有効である。いま，分析する微量成分が鉄鋼中にppm レベルで存在していると仮定すると，溶媒抽出法によって 鉄(III)を定量的に有機相に抽出除去する（試料中の鉄(III) の濃度が定量目的成分の濃度と同程度になるまで鉄(III)を 除去する）ためには，鉄(III)の分配比 $D （=$ (有機相の鉄 (III)濃度)/(水相の鉄(III)濃度)）が $10^{6}$ となる抽出系が必要 となる。現在，一般に鉄(III)の抽出に用いられている4-メ チル-2-ペンタノン $(\mathrm{MIBK})^{1)}$ では, 鉄(III)の分配比 $D$ が $10^{0.6}$ と小さく ${ }^{2)}$, 鉄(III)を定量的に除去するためには $4 \mathrm{~mol} \mathrm{dm}^{-3}$ 以上の塩酸溶液から 10 回繰り返し抽出操作を行 う必要がある。

一方, オルトリン酸エステルであるリン酸ジ（2-エチ ルヘキシル) (D2EHPA)は，水素結合によって形成された2 両体が金属イオンの周りを取り囲むような極めて疎水的な 構造をとることができるため, 高い分配比を持った抽出系 を設計するための抽出試薬となり得る。これまで， D2EHPAは主に希土類の分離に用いられており, Blake ら はウランの抽出に, Peppard ら ${ }^{4,5}$ はバークリウム(IV), およ びランタノイド等の抽出に用いている。一方, Kimura ${ }^{6,7)}$ は鉄(III)の抽出について検討し, D2EHPA-HCl抽出系にお ける鉄(III)の分配比Dは打よそ $10^{4}$ になることを報告して いる。これは鉄(III)-MIBK抽出系における分配比と比較し て，約2500倍も大きい。したがってD2EHPAを用いれば， MIBKによる鉄(III)の抽出よりも効率よく迅速に鉄(III)の 除去が行えるものと期待される。本研究では，鉄(III)
$0.1 \mathrm{~mol} \mathrm{dm}^{-3}$ 含む溶液から，鉄(III)を定量的に抽出除去す るための実験条件（抽出 $\mathrm{pH}$, 振とう時間, 有機溶媒）の検 討を行った。

\section{2. 実験}

\section{$2 \cdot 1$ 試薬}

D2EHPA 溶液：リン酸ジ（2-エチルヘキシル）を各種有 機溶媒に溶解し， $1.0 \mathrm{~mol} \mathrm{dm}^{-3}$ 溶液を調製した。

鉄 $(\mathrm{III})$ 溶液：硫酸アンモニウム鉄 $(\mathrm{III}) \cdot 12$ 水和物を $0.1 \mathrm{~mol} \mathrm{dm}^{-3}$ の塩酸に溶解したものを用いた。

試薬はすべて特級品を使用し, 水は超純水装置を通した ものを用いた。

\section{$2 \cdot 2$ 装置}

水相の鉄の定量には偏光ゼーマン式フレーム原子吸光光 度計を使用した。 $\mathrm{pH}$ 測定には複合電極を装備した $\mathrm{pH}$ メー ターを使用した。また，抽出にはKM型シェイカーを用い た（振とう数 360 回/分）。

\section{$2 \cdot 3$ 操作}

$1 \times 10^{-3} \sim 0.1 \mathrm{~mol} \mathrm{dm}^{-3}$ の鉄(III)を含み, $\mathrm{pH}$ を $1.0 \sim 2.8$ に調 整した水溶液 $20 \mathrm{~cm}^{3}$ と, $3 \times 10^{-2} \sim 1 \mathrm{~mol} \mathrm{dm}^{-3}$ の D2EHPA を 各種有機溶媒に溶解した溶液 $20 \mathrm{~cm}^{3}$ を分液ロートにとり一 定時間振とうし，静置分相後，水相の鉄の濃度を原子吸光 光度法により測定し，あわせて $\mathrm{pH}$ も測定した。

\section{3. 結果と考察}

\section{$3 \cdot 1$ 抽出時間, 抽出 $\mathrm{pH}, \mathrm{D} 2 \mathrm{EHPA}$ 濃度の検討}

水相の鉄(III)濃度を $1 \times 10^{-3} \mathrm{~mol} \mathrm{dm}^{-3}$ とし，有機溶媒に トルエンを用いて抽出時間と抽出 $\mathrm{pH}$ おびD2EHPA濃度 の影響について検討した。抽出時間の検討を行った結果を Fig. 1に示す。これより振とう時間 3 分以上で $\log D$ はほぼ 一定となっており, 本抽出系は比較的抽出速度も大きく, 


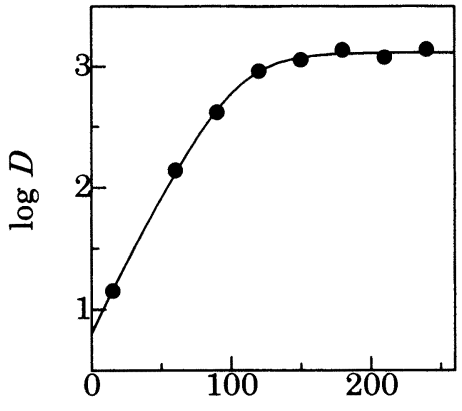

Shaking time/s

Fig. 1. Plot of $\log D$ against shaking time. $\left[\mathrm{Fe}^{\mathrm{III}}\right]$; $1 \times 10^{-3} \mathrm{~mol} \mathrm{dm}^{-3} ; \mathrm{pH}=2 ;[\mathrm{D} 2 \mathrm{EHPA}]_{\mathrm{org}}: 3 \times 10^{-2}$ mol dm${ }^{-3}$; solvent: toluene; shaking time: $3 \mathrm{~min}$.

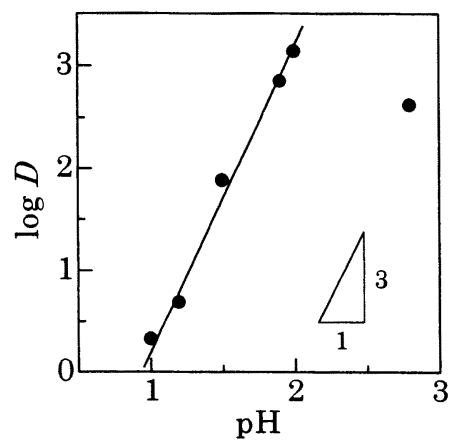

Fig. 2. Plot of $\log D$ against $\mathrm{pH}$. $\left[\mathrm{Fe}^{\mathrm{III}}\right]: 1 \times 10^{-3} \mathrm{~mol} \mathrm{dm}^{-3}$ [D2EHPA] $]_{\text {rg }}: 3 \times 10^{-2} \mathrm{~mol} \mathrm{dm}^{-3}$; solvent: toluene; shaking time: $3 \mathrm{~min}$

数分間の振とうで平衡に達することがわかる。抽出 $\mathrm{pH} の$ 影響について検討した結果を Fig. 2 に示す。

水素結合によって生成した D2EHPA(HA)の 2 量体が式 (1)の反応により鉄(III)を有機相に抽出するものと仮定す ると, 鉄(III)の分配比 $D\left(=\left[\mathrm{Fe}\left(\mathrm{HA}_{2}\right)_{3}\right]_{\mathrm{org}}\left[\mathrm{Fe}^{3+}\right]^{-1}\right)$ の対数は式 (2)で与えられる。

$$
\begin{aligned}
& \mathrm{Fe}^{3+}+3(\mathrm{HA})_{2, \mathrm{org}} \rightleftharpoons \mathrm{Fe}\left(\mathrm{HA}_{2}\right)_{3, \mathrm{org}}+3 \mathrm{H}^{+} . \\
& \log D=\log K_{\mathrm{ex}}+3 \log \left[(\mathrm{HA})_{2}\right]_{\mathrm{org}}+3 \mathrm{pH} \ldots .
\end{aligned}
$$

ここで, $K_{\mathrm{ex}}$ は抽出定数 $\left(=\left[\mathrm{Fe}\left(\mathrm{HA}_{2}\right)_{3}\right]_{\mathrm{org}}\left[\mathrm{H}^{+}\right]^{3}\left[\mathrm{Fe}^{3+}\right]^{-1}\left[(\mathrm{HA})_{2}\right]_{\mathrm{org}}^{-3}\right)$ を，添え字 org は有機相を表す。Fig. 2 より pHが 1 から 2 の 範囲では $\mathrm{pH}$ の増加にともない $\log D$ の值も増加し，またそ の傾きが 3 であることから，鉄(III)の抽出が式(1)に従っ て進行していることを示唆している。また $\mathrm{pH}$ 只以上に なると $\log D$ が減少することから，鉄(III)のヒドロキソ錯体 の生成により，抽出が不利になることを示している。した がって，本抽出における $\mathrm{pH}$ は最も高い分配比が得られた 2 とした。

次に, D2EHPA濃度の影響について検討した結果を Fig. 3に示す。鉄(III)の抽出が式(1)に従って進行する場合, 式 (2)の関係から, D2EHPA 濃度の增加にともない分配比も

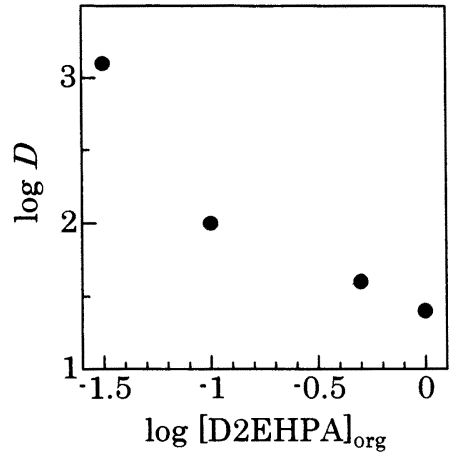

Fig. 3. Plot of $\log D$ against $\log [\mathrm{D} 2 \mathrm{EHPA}]_{\text {org. }}\left[\mathrm{Fe}^{\mathrm{III}}\right]$ : $1 \times 10^{-3} \mathrm{~mol} \mathrm{dm}^{-3} ; \mathrm{pH}=2$; solvent: toluene; shaking time: $3 \mathrm{~min}$.

Table 1. $\log D$ values of iron(III).

\begin{tabular}{cc}
\hline solvents & $\log D$ \\
\hline n-hexane & 1.17 \\
n-octane & 1.25 \\
carbon tetrachloride & 1.32 \\
toluene & 1.39 \\
n-heptane & 1.57 \\
benzene & 1.71 \\
chloroform & 1.85 \\
dichloromethane & 2.24 \\
MIBK & $>3$
\end{tabular}

[Fe $\left.\mathrm{Fe}^{\mathrm{III}}\right]: 1 \times 10^{-3} \mathrm{~mol} \mathrm{dm}^{-3} ; \mathrm{pH}=2 ; \quad[\mathrm{D} 2 \mathrm{EHPA}]_{\text {org }}: 1 \mathrm{~mol} \mathrm{dm}^{-3}$; shaking time: $3 \mathrm{~min}$.

增加するものと予測される。しかしながら，本抽出系では D2EHPA 濃度の増加にともない $\log D$ の值が減少する結果 となった。これは試薬濃度の増加にともない水相に分配す る D2EHPAの量が増大し，有機相と水相の分相が極端に悪 くなり，水相中にも鉄(III)錯体が分配しているためである と考えられる。したがって，高濃度のD2EHPAを用いた鉄 (III)の抽出においては, より高い分配比を与える溶媒の選 択が不可欠といえる。

\section{$3 \cdot 2$ 有機相に用いる溶媒の検討}

試料溶液中の鉄(III)の濃度は, 鉄鋼試料 $1 \mathrm{~g} を 200 \mathrm{~cm}^{3}$ の 酸に溶解した場合を考えると約 $0.1 \mathrm{~mol} \mathrm{dm}^{-3}$ になる。した がって，この場合，有機相の D2EHPAの濃度は $0.6 \mathrm{~mol}$ $\mathrm{dm}^{-3}$ 以上としなければならず，Fig. 3 の結果から，このま までは定量的な鉄の除去は行えないことがわかる。そこで， 本研究ではD2EHPA $1 \mathrm{~mol} \mathrm{dm}^{-3}$ の条件でもより定量的な鉄 (III)の抽出が可能な溶媒の選択について検討した。ここで は，溶媒として，トルエンのほか，へキサン，ヘプタン， オクタン, ベンゼン, 四塩化炭素, クロロホルム, ジクロ ロメタン，MIBKを用い，こ扎らの溶媒に $1 \mathrm{~mol} \mathrm{dm}^{-3} の$ D2EHPA を溶解したものをそれぞれ有機相に用いて鉄(III) 


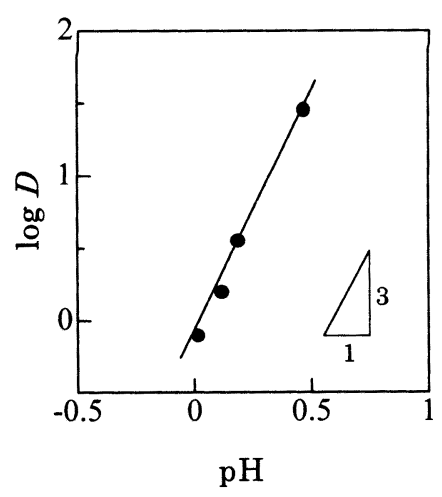

Fig. 4. Plot of $\log D$ against $\mathrm{pH}$. [Fe $\left.\mathrm{Fe}^{\mathrm{III}}\right]: 1 \times 10^{-4} \mathrm{~mol} \mathrm{dm}^{-3}$; [D2EHPA $]_{\text {org }}: 1 \times 10^{-2} \mathrm{~mol} \mathrm{dm}^{-3}$; solvent: MIBK; shaking time: $10 \mathrm{~min}$.

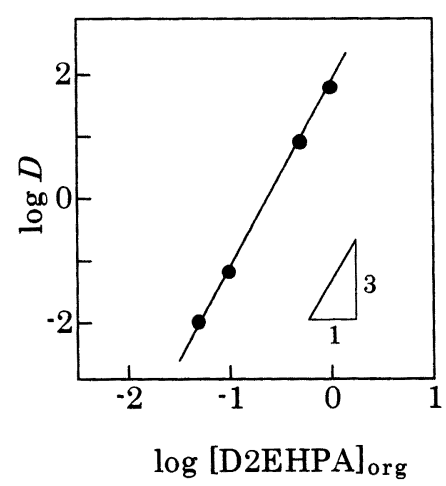

Fig. 5. Plot of $\log D$ against $\log [\mathrm{D} 2 \mathrm{EHPA}]_{\text {org }}\left[\mathrm{Fe}^{\mathrm{III}}\right]$ : $1 \times 10^{-4} \mathrm{~mol} \mathrm{dm}^{-3} ; \mathrm{pH}=0.2$; solvent: MIBK; shaking time: $10 \mathrm{~min}$.

の抽出を試みた。結果を Table 1に示す。これより，比較 的極性の高いクロロホルムやジクロロメタンを用いた場 合, 高い分配比を与える傾向にあるが, MIBKを溶媒とし て用いたときに最も高い分配比が得られることがわかる。 MIBKを溶媒に用いた場合の $\mathrm{pH}$ と D2EHPA濃度の影響に ついて検討した結果を Fig. 4 と 5 に示す。これより，いず れの場合もプロットの傾きは 3 となることから，MIBKを 溶媒に用いた場合は, D2EHPA濃度が高い領域においても 抽出は式(1)に従って進行し, D2EHPAの 2 量体が 3 分子配 位した鉄(III)錯体が有機相に抽出されていることを示唆し ている。また，MIBKを溶媒に用いた場合，分相も良好で あり, $\log D も 3$ 以上となるので, 2段階の抽出操作を行え ば鉄(III)の定量的な分離が達成できるものと考えられる。

\section{$3 \cdot 3$ D2EHPA/MIBK抽出による鉄(III)の分離}

D2EHPA MIBKに溶解した溶液を有機相に用いて，2
段階抽出操作により，鉄を含む試料溶液（鉄(III)濃度 $0.1 \mathrm{~mol} \mathrm{dm}^{-3}$ ) からの鉄(III)の分離除去を試みた。ここでは $\mathrm{pH} 2$ に調整した試料溶液 $20 \mathrm{~cm}^{3}$ と $1 \mathrm{~mol} \mathrm{dm}^{-3}$ の D2EHPA を含むMIBK溶液 $20 \mathrm{~cm}^{3}$ を分液ロートにとり 4 分間振とう した後，水相に放出されたプロトンによって低下した $\mathrm{pH}$ を $2 \mathrm{~mol} \mathrm{dm}^{-3}$ の水酸化ナトリウム溶液で再び 2 に調整し，4 分間振とうした。静置分相後, 有機相を除去し, 新たに $1 \mathrm{~mol} \mathrm{dm}^{-3}$ の D2EHPA を含む MIBK 溶液 $20 \mathrm{~cm}^{3}$ を分液口ー 卜に加え，4分間振とうした。静置分相後，水相の鉄濃度 を原子吸光光度法により定量した。その結果，2段階抽出 後の水相の鉄濃度は原子吸光光度計の検出限界（約 $\left.10^{-6} \mathrm{~mol} \mathrm{dm}^{-3}\right)$ 以下となり，本抽出法により定量的に鉄を 分離できることがわかった。

\section{4 他の成分の抽出挙動}

同様の操作で 5 種類の 2 価金属イオン (コバルト(II), 銅 (II), ニッケル(II), 鉛(II), 亜鉛(II)) の抽出挙動について検討 を行った。その結果, 本実験条件 $\left(\mathrm{pH}=2,[\mathrm{D} 2 \mathrm{EHPA}]_{\mathrm{org}}=\right.$

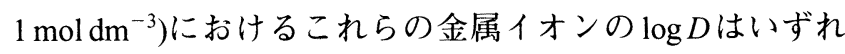
も-1以下となり，本抽出系では2価金属イオンの抽出能 は極めて小さいことがわかった。また，陰イオン成分とし て $\mathrm{NO}_{3}^{-}, \mathrm{SO}_{4}^{2-}$ の抽出挙動についても検討を行った結果， これらの成分も有機相には抽出されないことがわかった。

\section{4. 結論}

MIBKにD2EHPAを溶解した溶液を有機相を用いる鉄 (III)の抽出法は, 高濃度の鉄(III)を含む試料から効率よく, 簡便に鉄(III)を分離除去できることがわかった。また，本 抽出法における2価金属イオンと陰イオン成分の分配比は 鉄(III)の分配比と比較して極めて小さいことから，本法は 鉄鋼中のこれらの成分を分析する際の前処理法として有用 であると結論される。

\section{文献}

1) JIS G 1215: 鉄及び鋼中の硫黄の定量法, 日本規格協会, 東京, (1994).

2 ) Y.Marcus and A.S.Kertes: Ion Exchange and Solvent Extraction of Metal Complexes, Wiley-Interscience, New York, (1969), 950.

3 ) C.A.Blake, D.J.Crouse, C.E.Coleman, K.B.Brown and A.D.Klemers: USAEC ORNL-2172, (1956).

4 ) D.F.Peppard, S.W.Moline and G.W.Mason: J. Inorg. Nucl. Chem., 4 (1957), 344.

5 ) D.F.Peppard, G.W.Mason and S.W.Moline: J. Inorg. Nucl. Chem., 5 (1957), 141.

6 ) K.Kimura: Bull. Chem. Soc. Jpn., 33 (1960), 1038

7 ) K.Kimura: Bull. Chem. Soc. Jpn., 34 (1961), 63. 